\title{
Studies of $\mathrm{CH}_{3} \mathrm{NH}_{3} \mathrm{PbI}_{3}$ perovskite semiconductor deposited on $\mathrm{CdS}$ thin film for photovoltaic applications
}

\author{
Khursheed A. Parrey*, Nisha Devi, Anver Aziz and Asad Niazi \\ Department of Physics, Jamia Millia Islamia, New Delhi - 110025 India \\ *Email: khurshidphst25@gmail.com
}

Due to their excellent optical and electronic properties, halide perovskite semiconductors are being identified as promising light sensitizers for photovoltaics [1]. In this paper we report the synthesis and study of fundamental properties of methylammonium lead halide perovskite $\left(\mathrm{CH}_{3} \mathrm{NH}_{3} \mathrm{PbI}_{3}\right)$ films. We have also deposited the perovskite sensitizer on low temperature processed metal sulfide nanocrystalline thin films which act as charge transporting layers. The $\mathrm{CH}_{3} \mathrm{NH}_{3} \mathrm{PbI}_{3}$ and $\mathrm{CdS}$ have been grown on glass as well as on FTO substrates and characterised using XRD, UVvisible and FTIR spectroscopy, and SEM. The organometallic $\mathrm{CH}_{3} \mathrm{NH}_{3} \mathrm{PbI}_{3}$ is known to exhibit ambipolar charge transport and has a good band alignment compatibility with $\mathrm{CdS}$, facilitating charge transport. These properties can be used together to realize a simple heterostructure photovoltaic device without any hole transporting material over the perovskite.

Figure 1 shows the XRD pattern of the synthesized $\left(\mathrm{CH}_{3} \mathrm{NH}_{3}\right) \mathrm{PbI}_{3}$. All reflections are indexed by tetragonal unit cell with $\mathrm{a}=8.873$ $\AA$, and $\mathrm{c}=12.675 \AA$, the values are very close with previous reported [2] and grain size of 293.27 $\AA$ has been calculated by Scherrer equation as $\tau=\frac{K \lambda}{\beta \cos \theta}, \mathrm{K}$ is dimensionless factor close to unity, $\lambda$ is $\mathrm{x}$-ray wavelength, $\beta$ is full width half the maximum and $\theta$ is Brag angle. Figure 2 shows the scanning electron microscope (SEM) picture of the $\mathrm{CH}_{3} \mathrm{NH}_{3} \mathrm{PbI}_{3}$ sample. It can be observed that grain boundary is not clearly seen. From the picture, it is obviously seen that the film is tightly packed and composed of small, nanosized triangles, bullet type shapes and cubic grains appears. These different structures could prove useful for the device.

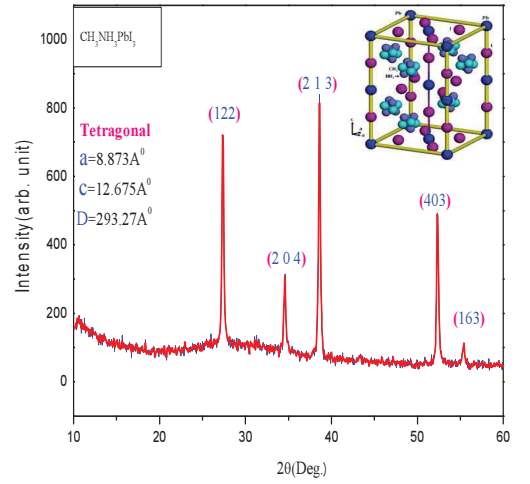

Figure 1: X-ray diffraction patterns of $\mathrm{CH}_{3} \mathrm{NH}_{3} \mathrm{PbI}_{3}$ with inset of tetragonal structure

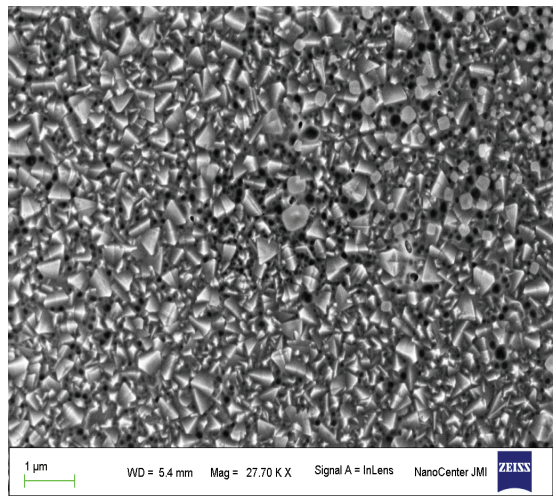

Figure 2: SEM image of perovskite film.

\section{References}

1. T. Miyasaka et. Al. Organometall halide perovskites as visible light sensitisers for photovoltaic cells. J. Am. Chem.Soc. 131, 60506051, 2009

2. T. Baikie et al Synthesis and crystal chemistry of the hybrid perovskite $\left(\mathrm{CH}_{3} \mathrm{NH}_{3}\right) \mathrm{PbI}_{3}$ for solid-state sensitised solar cell application., J. Mater. Chem. A, 15628; 2013 